\title{
Shijing, Pingdian and Cognitive Poetics
}

\author{
He LIN ${ }^{1} \mathrm{a}^{*}$, Jing DU ${ }^{2, b}$, \\ ${ }^{1}$ University of Electronic Science and Technology of China, China \\ ${ }^{2}$ Chengdu Aeronautic Polytechnic, China \\ alinhe@uestc.edu.cn, bcdavtc_dujing@cap.edu.cn \\ ${ }^{*}$ Corresponding author
}

\begin{abstract}
Keywords: Shijng, Pingdian, Cognitive Poetics, Chinese Classical Poetry.
\end{abstract}
\begin{abstract}
This article discusses the effectiveness of cognitive poetic frameworks like figure-ground, mental space, and prototype which are implied in and evidenced by traditional literary interpretations in the Chinese critical tradition. With examples from Shijing, it points out the relevance between cognitive poetic methods and Chinese traditional literary interpretation such as Pingdian. Combining modern cognitive poetic tools with huge resources of Chinese traditional interpretation, there may exist a new way of interpreting Chinese classical poetry and a hope of integrating indigenous poetic discourses with universal poetic principles.
\end{abstract}

\section{Introduction}

Often viewed as the first anthology of poetry in China, Shijing (translated variously as the Book of Songs, Book of Odes, or Classic of Poetry) has become one of the major sources for later generations of Chinese poets to draw from. Due to the anthology's privileged position in Chinese literary history, there exists a huge heritage of Shijing studies ${ }^{1}$, most of which use perspectives of philology, phonology, mingwu zhidu (thinglogy), rites and music culture. Since early 20th century, Shijing studies has been in progress but featured various new perspectives from domains like cultural anthropology, linguistics, literary esthetics, and psychology, which have exemplified a closely intertwined relation between human experiences, cognition and language.

This relation has also become a major concern for cognitive linguistics over the past decades, which believes that forms and structures of language are driven by human cognitive activities as well as cultural, social, physical and bodily experiences. With that said, literary works, be it written texts or oral ones, are rooted in fundamental and universal cognitive activities and life experiences. Appreciation and interpretation of literary works, therefore, can be viewed as attempts to probe the ways of generating meaning from the vantage point of mechanisms of language and cognition. Shijing, perhaps with Chinese classical poetry as a whole, and Shijing interpretations, can be understood in this way.

\section{Pingdian Tradition of Shijing}

As one of the basic Confucianist classics, Shijing enjoys a long-standing tradition of Jianzhu (exegesis) in Chinese literary culture, from which a new critical practice gradually came into being - the tradition of Pingdian (commentary), which focuses more on literariness of the anthology. Similar to Shihua (notes on classical Shi-poetry) and Cihua (notes on classical Ci-poetry) in Chinese traditional literary criticism, this type of interpretation should be viewed as a reader-oriented way of literary interpretation and acceptation [1]. Thus, traditional interpretations of Shijing begin to focus mainly on such aspects as historical origins, poetic forms, themes, influences, images, techniques, etc.,

\footnotetext{
1 According to Chuancai Xia, the 18th century bibliography book Siku Quanshu Zongmu Tiyao (Annotated General Catalogue of the Complete Collection of the Four Treasuries) has recorded 147 books and 1864 volumes that are about the study of Shijing. See C. Xia, Shijing Yanjiushi Gaiyao (Tsinghua University Press, Beijng, 2010), pp.223.
} 
most of them dealing with poetic devices like syntax, structure, style, and discourse. Take Poem No. 15 ("She Gathers the Duckweed") of Shijing as an example":

Where to gather the duckweed? / By the banks of the stream in the southern valley; /

Where to gather the pondweed? / In those pools left by the floods; //

Where to deposit gatherings? / In square baskets and round ones; /

Where to boil the herbs? / In those tripods and pans; //

Where shall be the rites? / Under the window in the ancestral chamber. /

Who superintends the sacrifice? / It is this reverent young girl [2].

On this poem J. Cheng and J. Jiang ${ }^{3}$ make an comment: "With five 'wheres' and one 'who', the question-answer pattern imposes a majestic power, which is like the rolling Yellow River-with extremely turbulent and whirling power it accumulated in the upper section, it suddenly pours into Jinmen. In the poem the last two lines is just like a plummet of the river-only until the end of the poem is the character [responsible for actions in the where-sentences] surfaced. [3]" For modern readers, this kind of comment looks more like a subjective understanding than a serious academic interpretation, though it is in fact an outstanding characteristic of Chinese traditional literary criticism.

For this subjectivity, the above-mentioned two scholars seem not to deny. As they write, "we are bold here to offer an aesthetic analysis in the interpretation of each poem in Shijing. These analyses are about either imagery or rhetoric, either sources or flaws. They may not be fully reasonable but suffice to be a guide to lead readers to wander about the poetic realms. [4]" Thus it can be seen that starting from intuitive judgment, Pingdian, sharing a cultural-psychological structure, aims to stimulate a cognitive reaction or mediating process among the reader's psychology. This mechanism gives us a hint to observe and probe of the relevance between cognitive poetic methods and Chinese traditional literary interpretation such as Pingdian.

\section{Insights from Cognitive Poetics}

Reuven Tsurs, who first used the term "cognitive poetics" in 1980, through his study of literary effect based on intuition or introspection consciousness in the western critical tradition, insists that cognitive poetics can be utilized "to interpret the interpretation", thus the subjective and introspective literary interpretation can be lifted to a more scientific and universal interpretative tool [5]. Peter Stockwell claims that Cognitive poetics can offer "a means of discussing interpretation whether it is an authorly version of the world or a readerly account, and how those interpretations are made manifest in textuality. [6]" Here we would like to discuss the relevance of three comparative poetic frameworks in addressing Shijing interpretation issues ${ }^{4}$.

\section{Figure-Ground}

Figure-ground, for instance, as one of the basic means in cognitive poetics ${ }^{5}$, was observed by gestalt psychology in the early twentieth century, which entitle us to perceive the three-dimensional world by differentiating an object (figure) from its background (ground). Thus with this framework we can have a better understanding of Chinese Pingdian criticism as showed in the aforementioned Poem No. 15 of Shijing.

Poem No.15 is actually a description of preparation for an ancestry worship ceremony. Based on the figure-ground mode, the process of gathering, depositing and boiling duckweeds and pondweeds as well as the loci for the rites turn into the "ground", against which the young girl becomes the

\footnotetext{
2 The English translation is my modification of a version by James Legge (see The She King or The Book of Songs). In his translation he fails to recognize the question patterns in lines 1,3,5,7, and 9 .

3 The two critics are famous for their book Shijing Zhuxi (Annotation of Shijing) which exemplifies the latest following of Pingdian tradition. Since its first print in 1991 the book has been reprinted 10 times by 2011 .

4 The figure-ground relation, of course, is a relative one in that the two can transmute into each other.

5 The major comparative poetic frameworks include figures/grounds, prototypes, text worlds, conceptual blending, mapping, schema, metaphor, etc. See P. Stockwell, Cognitive Poetics: An Introduction (Routledge, London, 2002).
} 
"figure". That means the "Who... ? It is..." pattern highlights the girl as the host of the ceremony. Interestingly, the dynamic process of working (as manifested by verbs "gather", "deposit" and "boiling") has now become a static background while the girl in the otherwise static background (as indicated by the last line in which there is no active verb) has been "in the limelight" —or as in the previously quoted Cheng's and Jiang's words, "the last two lines are just like a plummet of the river-only until the end of the poem is the person surfaced." It is here that we can perceive the value of both cognitive poetics and Chinese Pingdian tradition.

\section{Mental Space}

Another relevance of cognitive model can be found in the concept xing (stimulation). As one of the fundamental issues in Chinese poetics ${ }^{6}$, xing has been given various definitions, among which the 12th century Confucian scholar Zhu Xi's is a representative one: "Xing is a way of poetic presentation which follows the rule that things to be chanted are based on other things. [7]"

In most Shijing poems, we do find "other things" - plants, mountains, rivers, farming, customs, etc. How can these things, which are apparent reflections of agrarian living of Chinese ancients, be connected to something like lovesickness, complaint, or admonishment? In this respect, these things can be understood as building blocks of a "mental space". For instance, Poem No.48 ("Amid the Mulberries") is generally viewed as a poem about a young man's joy after dating with young ladies. The first two lines of each of the three stanzas repeat a question-answer pattern:

Oh for the plant, where is it? / In the fields of Mei it grows. /...//

Oh for the wheat, where is it? / To the north of Mei it grows. /...//

Oh for the root, where is it? / To the east of Mei it grows./... [8]

Although the things in the poem belong to different cognitive domains - the three directions ("fields", "north" and "east") are geographic concepts and the three plants ("plant", "wheat" and "root") botanical ones, they have virtually constructed a different mapping area-a mental space onto which three secret meetings with young ladies are projected. In this sense, xing can be viewed as a mapping mechanism to connect different worlds. Now it is perhaps no longer surprising to hear what Fang Yu-run, a Chinese critic in 19th century, comments on this poem: "Three persons, three places and three things. The three stanzas are different from each other, but the space through which the speaker expresses his expectation, invitation and sending off is the same. [9]"

\section{Prototype}

Poem No.110 ("The Climb") also contains an imaginary space built by different hills:

I ascend that tree-clad hill, / And look towards the residence of my father. / My father is saying, “... / ... / May he be careful, / That he may come back, and not remain there!" //

I ascend that bare hill, / And look towards the residence of my mother. / My mother is saying, “... / ... / May he be careful, / That he may come back, and not leave his body there!" //

I ascend the ridge, / And look towards the residence of my elder brother. / My brother is saying, “... / ... / May he be careful, / That he may come back, and not die!" [10]

The "tree-clad hill", "bare hill" and "ridge" have constructed not only a mental space for the theme of missing loved ones, but also a prototype of "climbing-missing". This explains why Fang Yu-run comments on this poem: "Those who are in military service would miss their homes when ascending a height. This is our human nature. [11]"

According to John Taylor, prototype can be understood as a schematic representation of a categorization [12]. In this regard, "climbing-missing" has become a "basic level category" in Chinese poetic tradition, which can be found in Poem No.3 ("I Was Gathering the Mouse-ear"), another Shijing poem of "missing": "I was ascending that rock-covered height," "I was ascending that lofty ridge," and "I was ascending that flat-topped height. [13]" In this sense it is safe to say that the

\footnotetext{
6 There are three basic modes of presentation in Shijing which have long been identified by scholars: $f u$ (exposition), $b i$ (comparison), and xing (stimulation). The last two modes have stirred numerous arguments among critics since Han Dynasty (206 B.C. -220 A.D.).
} 
"family resemblance" has made climbing a cognitive reference point that anticipates the universal "climbing-lyricism" in Chinese poetry. For example, it can be found in Qu Yuan's poem: "But as I ascended the bright reaches of heaven, / suddenly I looked down and saw my old home." ("Li Sao") [14], or Wang Wei's: "far away, I can almost see you reaching the summit, / dogwood berries woven into sashes, short one person" ("9/9, Thinking of My Brothers East of the Mountain") [15].

\section{Conclusion}

Cognitive poetics, as Stockwell claims, "means a thorough re-evaluation of all of the categories with which we understand literary reading and analysis. [16]" In this sense, the above mentioned cognitive poetic frameworks like figure-ground, mental space, and prototype have evaluated the relevance between cognitive poetic methods and Chinese traditional literary interpretation such as Pingdian. Thus if combining modern cognitive poetic tools with huge resources of Chinese traditional interpretation, there may exist not only a new way of interpreting Shijing and other Chinese classical poems, but also a hope of integrating indigenous poetic discourses with universal poetic principles.

\section{Acknowledgement}

This work is supported by the Fundamental Research Funds for the Central Universities of China (Grant No. ZYGX2015J164).

\section{References}

[1] H. Zhang, Shijing Pingdian Studies, PhD thesis, Fudan University, 2008, pp.3.

[2] J. Legge (ed. and trans.), The She King or The Book of Songs, in The Chinese Classics Vol.4, SMC Reprint, Taipei, 1983, pp.25.

[3] J. Cheng and J. Jiang, Shijing Zhuxi, Zhonghua Shuju, Beijing, 1991, pp.36.

[4] J. Cheng and J. Jiang, Shijing Zhuxi, Zhonghua Shuju, Beijing, 1991, pp.3.

[5] X. Su, Guwai renzhi shixue yanjiu gaiguan, Waiguo Yuwen 2 (2009) 7-10.

[6] P. Stockwell, Cognitive Poetics: An Introduction, Routledge, London, 2002, pp5.

[7] X. Zhu, Shi Ji Zhuan, Zhonghua Shuju, Beijing, 2011, pp.2.

[8] R. Wang (trans.), The Book of Songs, Hunan People's Publishing House, Changsha, 2008, pp.83-85.

[9] Y. Fang, Shijing Yuanshi, Zhonghua Shuju, Beijing, 1986, pp.161.

[10] J. Legge (ed. and trans.), The She King or The Book of Songs, in The Chinese Classics Vol.4, SMC Reprint, Taipei, 1983, pp.167-168.

[11] Y. Fang, Shijing Yuanshi, Zhonghua Shuju, Beijing, 1986, pp.246.

[12] J. Taylor, Linguistic Categorization: Prototypes in Linguistic Theory, Clarendon Press, Oxford, 1995 , pp.59.

[13] J. Legge (ed. and trans.), The She King or The Book of Songs, in The Chinese Classics Vol.4, SMC Reprint, Taipei, 1983, pp.8-9.

[14] B. Watson (ed. and trans.), The Columbia Book of Chinese Poetry, SMC Reprint, Taipei, 1983, pp.66.

[15] W. Wang, The Selected Poems by Wang Wei, trans. David Hinton, New Directions, New York, 2006, pp.1. 
[16] P. Stockwell, Cognitive Poetics: An Introduction, Routledge, London, 2002, pp.6. 